BLS 34, No 1 2008. DOI: http://dx.doi.org/10.3765/bls.v34i1.3552

(published by the Berkeley Linguistics Society and the Linguistic Society of America)

\title{
Phonosemantic Evidence for the Mimetic Stratum in the Japanese Lexicon $^{1}$
}

KIMI AKITA

Kobe University

\section{Introduction}

This paper pursues phonosemantic evidence for the existence of the mimetic (or sound-symbolic, ideophonic) category in Japanese, especially with respect to lexical stratification. Specifically, I will discuss experimentally whether there is some difference in sound-symbolic phenomena between mimetic and nonmimetic words, or between the Mimetic stratum and other strata, in particular the Native stratum.

The organization of this paper is as follows. In Section 1, I will introduce two major standpoints toward the vocabulary stratification issue-one gives an independent status to mimetics and the other does not-in Japanese linguistics. In Section 2, citing the experimental consideration in Akita (2008), I will present a morphophonological definition of the mimetic category. Based on the idea, in Section 3, I will discuss on an experimental ground whether there is some difference in sound-symbolic effects between morphophonologically mimetic and nonmimetic words. Finally, in Section 4, I will conclude in favor of the viewpoint that posits a special (phono)semantic status for mimetics that it can be the case that sound symbolism works more effectively in mimetics than nonmimetics.

\section{Three vs. Four Lexical Strata in Japanese}

\subsection{Lexical Stratification in Etymology and Phonology}

In lexicological, etymological, and phonological studies, there have been two major hypotheses concerning lexical stratification of Japanese (for other hypotheses see Itô and Mester 1999; Tateishi 2003; Kurisu 2006). One is the three strata hypothesis, which is mainly taken in etymological descriptions (see Tokieda et al.

\footnotetext{
${ }^{1}$ This paper represents part of the author's research supported by Grant-in-Aid for JSPS Fellows (\#19.536). I am grateful to the BLS 34 audience for their insightful comments and criticisms. My greatest acknowledgment goes to Hajime Takeyasu, who provided generous support and advice in statistical analyses. I also thank Yo Matsumoto, Natsuko Tsujimura, and Benjamin Bergen, all of whom gave me lots of constructive comments. Remaining errors and shortcomings are of course my own.
} 


\section{Kimi Akita}

1955:355; Miyajima 1977). The three strata are the Native (or Yamato) stratum, the Sino-Japanese stratum, and the Foreign (or Loanword) stratum. This hypothesis reflects where a word comes from: Japanese original, Chinese, or English (or other languages including French, German, and Portuguese).

The other hypothesis posits the fourth lexical stratum. Concretely, it separates the Mimetic stratum out of the (etymologically) Native stratum. This idea is the mainstream in current Japanese phonology (see McCawley 1968; Itô and Mester 1995; Fukazawa et al. 1998). The reason for positing the fourth stratum is phonological differences between mimetics and nonmimetics. For example, Itô and Mester (1995) argue for this latter hypothesis based on the unique constraint violation pattern of mimetics cited below. Mimetics are sole candidates for the membership of the phonological group which allows a single [p] (e.g. p $a^{\wedge}$ tipati, poro $\left.{ }^{\wedge} r i\right)$ but does not allow a voiceless obstruent following a nasal within a morpheme (e.g. $\left.{ }^{*} k o N \boldsymbol{k} a^{\wedge} r i,{ }^{*} p i N \boldsymbol{t} a^{\wedge} r i\right)$ and a voiced geminate cluster (e.g. *koQga^ri, ??heQnahena) (see also Kurisu 2006; Akashi 2007). ${ }^{2}$

Phonological uniqueness of mimetics:

Native
Sino-Japanes
Mimetic
Foreign

$\begin{array}{ccc}{[\mathrm{p}]} & \mathrm{NT} & \mathrm{DD} \\ * & * & * \\ * & \sqrt{ } & * \\ \sqrt{ } & * & * \\ \sqrt{ } & \sqrt{ } & \sqrt{ }\end{array}$

(adapted from Itô and Mester 1995:820)

My question regarding this issue is quite simple and naïve: is there any (phono)semantic basis for the separate status of the Mimetic stratum? This question is a natural one in light of the general assumption that mimetics are semantically peculiar (see Hamano 1998 among others).

\subsection{Lexical Stratification in Phonosemantics}

Phonosemantics is a (psycho)linguistic field that investigates the motivated or iconic properties of systematic correspondences found between sound and meaning of words within and sometimes across languages (Hinton et al. 1994; Magnus 1999). Some phonosemantic studies, such as Kawahara et al. $(2005,2008)$ and Shinohara et al. (2007), have pointed out the existence of sound-symbolic phenomena in nonmimetic words in favor of the three strata hypothesis (i.e. without distinction between the Native and the Mimetic strata; see also Makino 2007). ${ }^{3}$ In

\footnotetext{
${ }^{2}$ Abbreviations and symbols used in this paper are as follows: $\mathrm{C}=$ consonant; $\mathrm{N}=$ moraic nasal; $\mathrm{Q}=$ the first half of a geminate cluster; $\mathrm{V}=$ vowel; ${ }^{\wedge}=$ accent nucleus, pitch fall (specified only for mimetics)

${ }^{3}$ Given that the traditional three- and four-strata hypotheses are purely based on lexicology, etymology, or phonology, it might be inappropriate to discuss a semantic issue in the same framework. In this respect, "the Mimetic stratum" here should be replaced with "the mimetic category."
} 


\section{Phonosemantic Evidence for the Mimetic Stratum}

fact, this cross-stratal characteristic is why sound symbolism is sound symbolism-more explicitly, why "sound symbolism" is deliberately distinguished from "sound-symbolic words" (i.e. mimetics) (Tamori and Schourup 1999).

If phonosemantic properties are not specific to mimetics, where does the sense of semantic peculiarity of mimetics come from? A possible moderate solution to this apparently contradictory situation is the following:

A hypothesis on the phonosemantic status of mimetics:

The mimetic category is the best locus of sound symbolism.

In preparation for an experimental examination of this hypothesis, I will establish a formal definition of mimetics in the next section.

\section{Morphophonological Definition of Mimetics}

This section, based on the findings in Akita (2008), gives a clear definition to Japanese mimetics in terms of their morphophonology. The declaration of the definition will offer a basis of the discussion in Section 3, where what is mimetic plays an essential part.

Despite the fact that mimetics sound "unambiguously mimetic" to native Japanese speakers (Hamano 1998:219; Tamori and Schourup 1999:6), definition of mimetics has been one of the biggest puzzles in mimetic studies (for similar puzzles in other languages see Abelin 1999; Wiltshire 1999; Newman 2001). Hamano (1998:6-7) discusses this difficulty from four aspects. First, the semantic idiosyncrasy of mimetics (i.e. their ability to imitate nonlinguistic sounds or manners by means of linguistic sounds) without a firm criterion is too unreliable to use in an objective definition. Second, indeed, some morphological processes, such as reduplication (e.g. metyametya, to^kotoko) and emphatic consonant insertion (e.g. $b i \boldsymbol{Q} k u^{\wedge} r i, k o N g a^{\wedge} r i$ ), frequently take place in mimetics. However, these are neither a necessary nor sufficient condition for mimetics. For example, neither morphological property is present in mimetics like hura^ri and gunya $Q^{\wedge}$. Moreover, these properties are shared with not a few nonmimetic words like reduplicated nouns like hitobito 'people' (< hito 'person') and intensified expressions like $\operatorname{Su}\{\boldsymbol{Q} / \boldsymbol{N}\}$ gee! 'Grrreat!' (< sugoi 'great'). Third, we can observe some crosscategorial traffic into and out of the mimetic category (e.g. simi^zimi $<$ simu 'soak' (a nonmodern verb); noNbi^ri < nobu 'get long' (a nonmodern verb); awate-huta-meku 'be flustered' < huta (a nonmodern mimetic root)). Hence, a historical/etymological definition does not necessarily work well. Finally, there is a phonological and grammatical phenomenon only observable in mimetics: [p]initial adverbs that take the quotative particle -to are mimetic (e.g. po^tapota-to, pita^ri-to; cf. [p]-initial loanword adverbs like pawahuru-\{ni/*to\} 'powerfully' and parareru-\{ni/*to\} 'in parallel'). This statement is true but far from defining the entire mimetic category.

In what follows, I will introduce an experimental study that shows that a set of morphophonological templates successfully define the category. 


\section{Kimi Akita}

\subsection{Morphophonological Templates for Mimetics}

In the challenging situation stated above, Akita (2008) proposes that satisfying one of the limited number of morphophonological templates (or constructions) is the crucial condition for a canonical member of the mimetic category in Japanese. This proposal stems from the fact that almost all mimetics can be classified into one of the fifteen formal classes listed below:

Morphophonological templates for Japanese mimetics:

a. For CV-roots:

$\mathrm{CVQ}^{\wedge}, \quad \mathrm{CV}\left(^{\wedge}\right) \mathrm{N}\left({ }^{\wedge}\right), C \mathrm{CViQ}^{\wedge}, \quad \mathrm{CV}\left(^{\wedge}\right) \mathrm{V}\left(^{\wedge}\right), \quad \mathrm{CV}^{\wedge} \mathrm{V}-\mathrm{CVV}, \mathrm{CVV}-\mathrm{CVV}$, $\mathrm{CV}^{\wedge} \mathrm{N}-\mathrm{CVN}, \mathrm{CVN}-\mathrm{CVN}, \mathrm{CV}^{\wedge} \mathrm{i}-\mathrm{CVi}$

b. For CVCV-roots: ${ }^{4}$

$\left.\left.\mathrm{CVCVQ}^{\wedge}, \mathrm{CVCV}^{\wedge}\right) \mathrm{N}^{\wedge}\right), \mathrm{CVCV}^{\wedge} \mathrm{ri}, \mathrm{CVCCV}^{\wedge} \mathrm{ri}, \mathrm{CV}^{\wedge} \mathrm{CV}^{-} \mathrm{CVCV}$, CVCV-CVCV

As Hamano (1998) discusses in detail, Japanese mimetics can be basically reduced to one- or two-mora roots. For example, $s u Q^{\wedge}$ and $p y o^{\wedge} N p y o N$ can be analyzed as based on the one-mora (CV) roots $s u$ and pyo, respectively. Likewise, poQka^ri and meromero can be reduced to the two-mora (CVCV) roots poka and mero, respectively. Seen differently, one- and two-mora mimetic roots enter one of the nine and six morphophonological templates in (3), respectively. For example, $s u Q^{\wedge}$ fills the template $\mathrm{CVQ}^{\wedge}$, $p y o^{\wedge} N p y o N$ fills $\mathrm{CV}^{\wedge} \mathrm{N}-\mathrm{CVN}$, poQka $r i$ fills $\mathrm{CVCCV}^{\wedge}$ ri, and meromero fills $\mathrm{CVCV}-\mathrm{CVCV}$. As an illustration of the wide coverage of the templates, Akita (2008) shows how many mimetics registered in Kakehi et al. (1996) (with some supplementation, 1,652 in total), one of the largest Japanese mimetic dictionaries, fill the templates.

a. Mimetics satisfying a template:

Reduplicative templates (e.g. bu^ubuu, do^kidoki):

$1627(98 \%)$

- $Q^{\wedge}$-ending templates (e.g. sa $Q^{\wedge}$, doki $Q^{\wedge}$ ):

$785(48 \%)$

$\left.-\left({ }^{\wedge}\right) N^{\wedge}\right)$-ending templates (e.g. $p o N^{\wedge}$, doki^ $N$ ):

$269(16 \%)$

$\mathrm{CVCV}^{\wedge}$ ri (e.g. huwa^ri, doki^ri):

$122(7 \%)$

$\mathrm{CVCCV}^{\wedge}$ ri (e.g. geNna^ri, doQki^ri):

$146(9 \%)$

$133(8 \%)$

Derivatives (e.g. kururi $^{\wedge}$, paQpaQ ${ }^{\wedge}$ ):

$117(7 \%)$

Fossilized templates (e.g. $\left.h a Q^{\wedge} s i, h u Q k u^{\wedge} r a\right):^{5}$

$55(3 \%)$

b. Mimetics satisfying no template (e.g. hihii^ $N$, ogya $a^{\wedge}$ ): $25(2 \%)$

Akita's (2008) templatic approach is critically different from previous ones in two points. First, it emphasizes accentuation (i.e. presence/absence and position

\footnotetext{
${ }^{4}$ Throughout this paper, in naming templates, I will omit the numbers indicating the positions of consonants and vowels. Note that $\mathrm{C} 1$ and $\mathrm{C} 2$ are basically different in Japanese mimetics (Hamano 1998).

5 "Fossilized templates" include templates that were once productive (e.g. $\left.\mathrm{CV}^{\wedge} \mathrm{CCV}, \mathrm{CVCCV}{ }^{\wedge} \mathrm{ra}\right)$ (Yamaguchi 2002:34-5,39). Now mimetics filling these templates give some old-fashioned tones.
} 


\section{Phonosemantic Evidence for the Mimetic Stratum}

of "^^") in setting up the mimetic templates (cf. Lu 2006). Second, it uses the fifteen templates as a set which as a whole participates in the definition of mimetics.

\subsection{Morphophonological Templates and Mimeticity}

Akita (2008) submits an experimental piece of evidence for the validity of the templatic definition of Japanese mimetics. The experiment measures the "mimeticity" of four types of nonsense words (i.e. sequences of phonemes that do not exist as a word in the vocabulary of Japanese). 100 stimulus words in total were created under two parameters: namely, whether to fill one of the templates for two-mora mimetic roots in (3b) and whether to possess one of the three segmental properties below that Tamori and Schourup (1999) claim are unique to mimetics.

Segmental features "unique to mimetics":

a. Free from sequential voicing in reduplication (e.g. ${ }^{*} k{ }^{\wedge}$ rogoro; cf. hitobito 'people')

b. Free from nasalization of $\mathrm{C} 1 / \mathrm{g} /$ of a reduplicant (e.g. * ${ }^{*} a^{\wedge}$ yayaya; cf. kaminami 'gods')

c. High frequency of initial [p] (about one-sixth of all; e.g. pari $N^{\wedge}$, pi^kupiku, poQku^ri)

(adapted from Tamori and Schourup 1999:210-1)

Thirty native Japanese speakers were asked to rate the mimeticity of each audiorecorded word presented twice at random via a headphone in a quiet room. Ratings were made on a seven-graded scale: from " 1 " (does not sound mimetic at all) to "7" (sounds very mimetic) with " 4 " as moderate.

Results were consistent with the templatic definition hypothesis. Mean scores (recalculated between 0 and 1) for the four types of words are given in (6) with some stimulus samples.

(6) Results of the mimeticity experiment (Akita 2008):

\begin{tabular}{|c|c|c|}
\hline Templatic/segmental factor & $\begin{array}{l}\text { Stimulus samples } \\
\text { pu^sipusi, paruN } N^{\wedge}\end{array}$ & $\begin{array}{c}\text { Mean scores } \\
.65\end{array}$ \\
\hline$\sqrt{ } / *$ & hemo $\wedge^{\wedge} r i, s^{\wedge}$ mozemo & .57 \\
\hline$* / \sqrt{ }$ & pa`muto, pekiro ${ }^{\wedge} i w a$ & .10 \\
\hline$* / *$ & me^toa, ponusame & .15 \\
\hline
\end{tabular}

A two-way repeated measures analysis of variance revealed that the main effects of both templatic and segmental factors were significant (templatic factor: $F(1,2998)=94.14, p<.001$; segmental factor: $F(1,2998)=7.33, p<.01)$. However, the effect sizes of these factors showed a remarkable contrast. As the partial eta squares (from 0 to 1 ) indicate, more than the half of the results were determined by the templatic condition (templatic factor: $\eta p^{2}=.66$; segmental 


\section{Kimi Akita}

factor: $\left.\eta p^{2}=.003\right)$. This consequence offers strong support to the idea that the membership of the mimetic category in Japanese is guaranteed by the aforementioned set of morphophonological templates. In the following section, I will use the template satisfaction discussed here as a criterion of mimetics.

\section{Morphophonological Templates and Sound-Symbolic Effects}

In order to examine the hypothesis put forward in (2) above (i.e. "the mimetic category is the best locus of sound symbolism"), I conducted an experiment that compared sound-symbolic effects in mimetics with those in nonmimetics. I limited my concern to what is called magnitude symbolism (or size sound symbolism) of vowels and consonants, which has been most widely discussed in the sound symbolism studies since Sapir (1929). For example, numerous experiments have been done to show that words starting with a voiced consonant (e.g. beep) tend to represent bigger referents than those starting with a voiceless consonant (e.g. peep). Likewise, words with a low/broad vowel (e.g. $m \boldsymbol{a l}$ ) are said to represent larger referents than those with a high/narrow vowel (e.g. mil) in many languages (to mention a few, Johnson 1967; Ultan 1978; Diffloth 1994).

\section{1. $\quad$ Method}

I asked twenty native Japanese speakers (11 females, 9 males; from 19 to 55 years old, 29.25 on average) to rate how large the imagined referents (e.g. a desk) of thirty-six nonsense words seemed. The rating scale was from "1" (small) to "4" (large). Twelve audiorecorded triads of CVCV-based words were created with C1 /g, z, b; k, s, p/, V1 /a/ or /i/, and CV2 /no/. As listed in (7), all possible combinations of $\mathrm{C} 1$ and $\mathrm{C} 2$ were put in a nonmimetic template (i.e. $\mathrm{CV}^{\wedge} \mathrm{CV}$ ) and two mimetic templates identified in Section 2 (i.e. $\mathrm{CV}^{\wedge} \mathrm{CV}-\mathrm{CVCV}$ and $\mathrm{CVCV}^{\wedge}$ ri). ${ }^{6}$ These male vocal stimuli were recorded on Audacity, an audioeditor-recorder, and presented twice per word at random on Windows Media Player or Apple QuickTime Player. Every test trial followed ten practice questions.

(7) A list of stimuli:

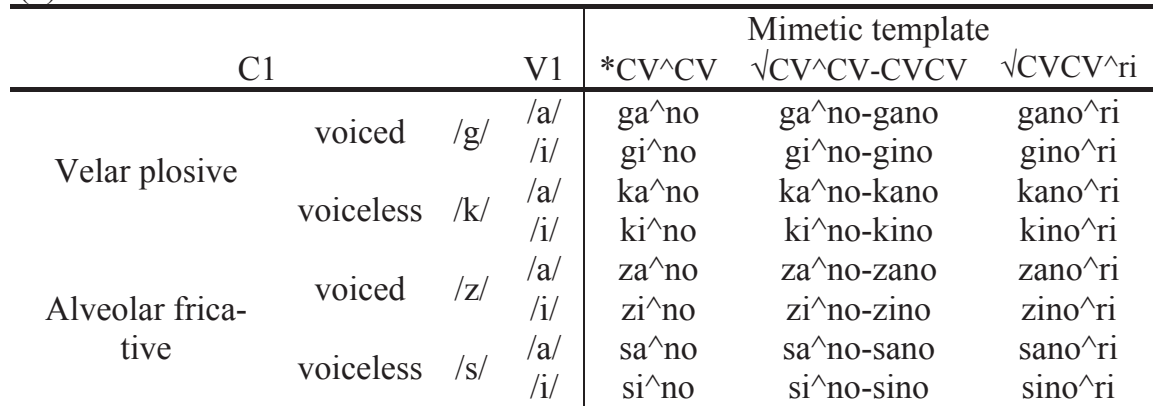

\footnotetext{
${ }^{6}$ I used two mimetic morphophonological templates in case magnitude-symbolic effects are ascribed to a particular mimetic template, not mimetic templates in general (see also footnote 8).
} 


\section{Phonosemantic Evidence for the Mimetic Stratum}

\begin{tabular}{|c|c|c|c|c|c|c|}
\hline Bilabial plosive & $\begin{array}{c}\text { voiced } \\
\text { voiceless }\end{array}$ & $\begin{array}{l}/ \mathrm{b} / \\
/ \mathrm{p} /\end{array}$ & $\begin{array}{l}/ \mathrm{a} / \\
/ \mathrm{i} / \\
\mathrm{a} / \\
\mathrm{i} /\end{array}$ & $\begin{array}{l}\mathrm{ba}^{\wedge} \mathrm{no} \\
\mathrm{bi}^{\wedge} \mathrm{no} \\
\mathrm{pa}^{\wedge} \mathrm{no} \\
\mathrm{pi}^{\wedge} \mathrm{no}\end{array}$ & $\begin{array}{l}\mathrm{ba}^{\wedge} \text { no-bano } \\
\mathrm{bi}^{\wedge} \text { no-bino } \\
\mathrm{pa}^{\wedge} \text { no-pano } \\
\mathrm{pi}^{\wedge} \text { no-pino }\end{array}$ & $\begin{array}{l}\text { bano }^{\wedge} \mathrm{ri} \\
\text { bino }^{\wedge} \mathrm{ri} \\
\text { pano }^{\wedge} \mathrm{ri} \\
\text { pino }^{\wedge} \mathrm{ri}\end{array}$ \\
\hline
\end{tabular}

\subsection{Prediction}

A specific prediction within Hypothesis (2) is as follows. If magnitude symbolism is more effective-i.e. the largeness effects of voiced Cs and /a/ and the smallness effects of voiceless Cs and /i/ are promoted-in mimetics, then the difference in magnitude symbolism between a voiced $\mathrm{C}$ and a voiceless $\mathrm{C}$ or between $/ \mathrm{a} / \mathrm{and} / \mathrm{i} /$ will be greater in morphophonologically mimetic (i.e. $\mathrm{CV}^{\wedge} \mathrm{CV}-\mathrm{CVCV}, \mathrm{CVCV}^{\wedge}$ ri) words than in morphophonologically nonmimetic (i.e. $\mathrm{CV}^{\wedge} \mathrm{CV}$ ) words.

\subsection{Results}

Results of the experiment partially supported the hypothesis. First of all, in accordance with the previous findings, nonmimetic as well as mimetic words instantiated magnitude symbolism. A three-way analysis of variance showed the significance of the main effects of all the three factors (voicedness of C1: $F$ (11, $708)=457.18, p<.001 ; / \mathrm{a} / \mathrm{vs}$. /i/ of V1: $F(11,708)=37.50, p<.001$; mimetic vs. nonmimetic: $F(11,708)=4.70, p<.01)$. Intriguingly, the effect size of the voicedness factor was overwhelmingly greater than those of the other two factors (voicedness: $\eta p^{2}=.39$; /a/ vs. $/ \mathrm{i} /: \eta p^{2}=.05$; mimetic vs. nonmimetic: $\eta p^{2}=.01$ ).

What is directly concerned with the present discussion is the mimeticity factor. Subjects' ratings were recalculated in order that "large" and "small" judgments have positive and negative numbers, respectively (from " -1 " to "+1" with " 0 " as moderate). The graphs in (8) give a mean score for each stimulus, comparing each two roots constituting a minimal pair with respect to the voicedness of their first consonants. In each graph, the first pair of bars indicates mean scores for nonmimetic stimuli (i.e. $\mathrm{CV}^{\wedge} \mathrm{CV}$ ), and the second and third pairs of bars indicate those for mimetic stimuli (i.e. $\mathrm{CV}^{\wedge} \mathrm{CV}-\mathrm{CVCV}$ and $\mathrm{CVCV}^{\wedge}$ ri, respectively).

Mean scores for magnitude symbolism of C1 (voiced vs. voiceless):

a. gano vs. kano

b. gino vs. kino

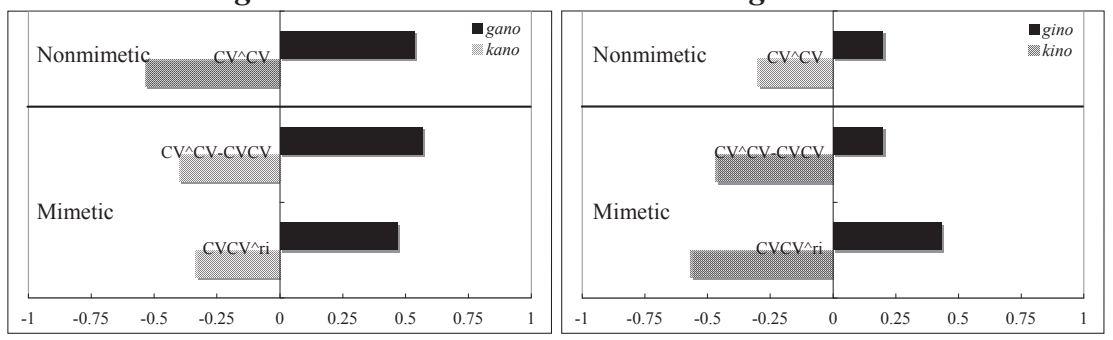




\section{Kimi Akita}

c. zano vs. sano

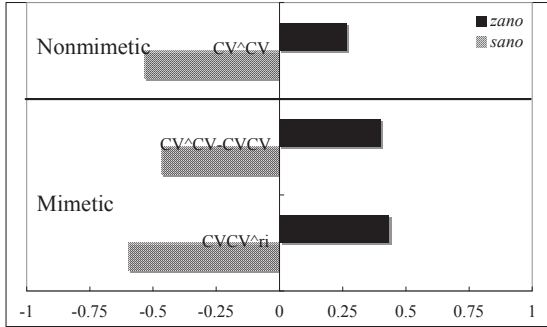

e. bano vs. pano

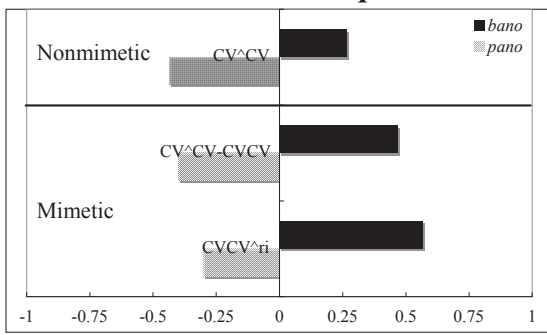

d. zino vs. sino

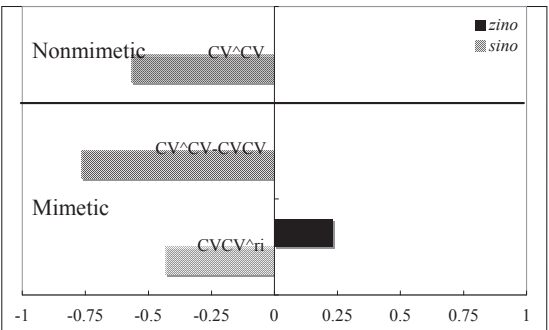

f. bino vs. pino

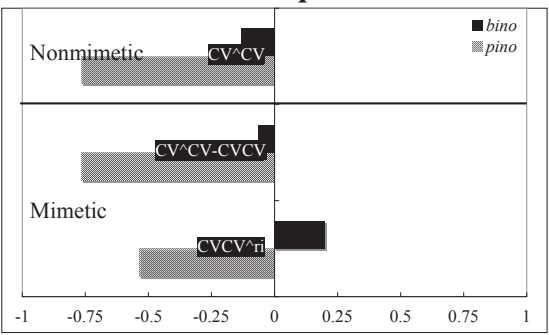

The graphs in (9) compare each two roots constituting a minimal pair with respect to their first vowels (i.e. /a/ and /i/).

(9) Mean scores for magnitude symbolism of V1 (/a/ vs. /i/):

a. gano vs. gino

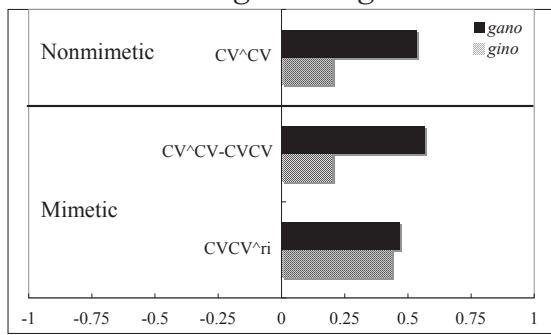

b. kano vs. kino

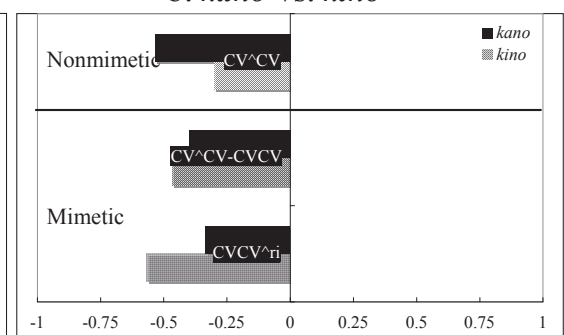




\section{Phonosemantic Evidence for the Mimetic Stratum}

c. zano vs. zino

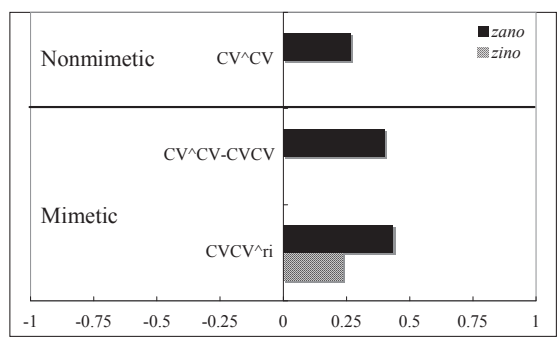

e. bano vs. bino

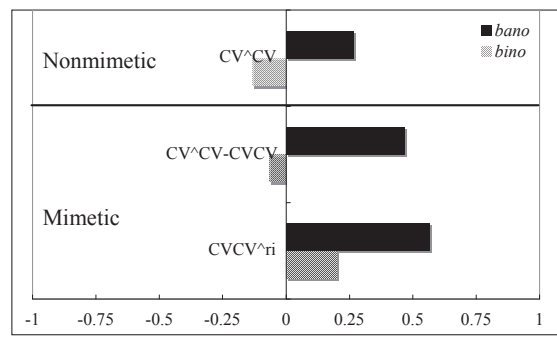

d. sano vs. sino

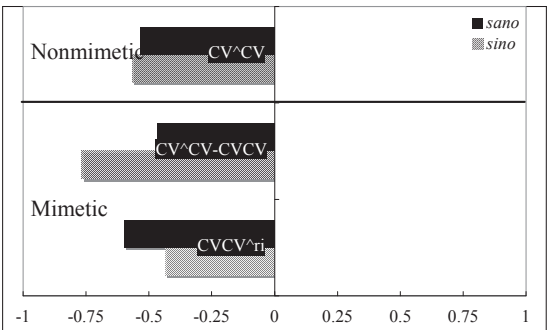

f. pano vs. pino

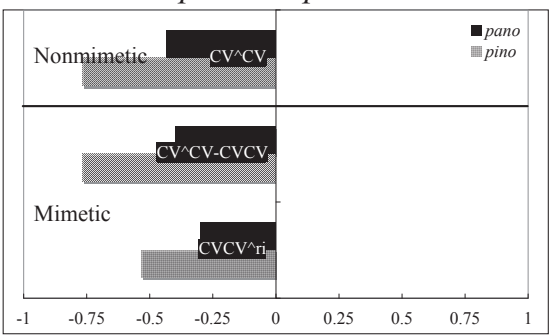

\subsection{Analysis and Discussion}

For examination of the prediction set in Section 3.2, differences between the scores for nonmimetic stimuli and those for mimetic stimuli-namely, between $\mathrm{CV}^{\wedge} \mathrm{CV}$ and $\mathrm{CV}^{\wedge} \mathrm{CV}-\mathrm{CVCV}$ stimuli and between $\mathrm{CV}^{\wedge} \mathrm{CV}$ and $\mathrm{CVCV}^{\wedge}$ ri stimuli-were calculated. Statistical comparisons were drawn between nonmimetic $\mathrm{CV}^{\wedge} \mathrm{CV}$ and mimetic $\mathrm{CV}^{\wedge} \mathrm{CV}-\mathrm{CVCV}$ scores and between nonmimetic $\mathrm{CV}^{\wedge} \mathrm{CV}$ and mimetic $\mathrm{CVCV}^{\wedge}$ ri scores. Post-hoc tests (one-tailed Wilcoxon signed-rank tests) for the Friedman test revealed that most mimetic-nonmimetic pairs form no significant contrast in their magnitude-symbolic effects. ${ }^{7}$ However, in two cases, mimetics produced significantly greater magnitude-symbolic effects than nonmimetics $\left((8 \mathrm{~b})\right.$ gi^no-minus-ki^no $<$ gino`ri-minus-kino ${ }^{\wedge} r i: Z(19)=-2.58, p<$ $.007=$ adjusted significance level; (9b) $k a^{\wedge}$ no-minus- $k i^{\wedge} n o<k a n o^{\wedge} r i$-minus$\left.k_{i n o}{ }^{\wedge} r i: Z(19)=-2.13, p<.03\right)$. Moreover, approaching significance was obtained for two cases ((8b) gi^no-minus- $k i^{\wedge}$ no $<$ gi^nogino-minus-ki^nokino: Z (19) $=-1.51, p<.07$; (9d) $s a^{\wedge}$ no-minus-si^no $<$ sa^nosano-minus-si^nosino: $Z(19)=$ $-1.80, p<.07)$. What is crucial for the current context is the fact that there was only one case in which nonmimetic words surpass mimetic words in their magnitude-symbolic effects - although merely with approaching significance ((9d) $s a^{\wedge}$ no-minus-si^no $>$ sano $^{\wedge} r i$-minus-sino $\left.{ }^{\wedge} r i: Z(19)=-1.51, p<.07\right)$. This set of

\footnotetext{
${ }^{7}$ The Friedman and the Wilcoxon tests, nonparametric alternatives to repeated measures ANOVA and the paired Student's $t$-test, respectively, were used because the current experiment employed an ordinal scale (see Section 3.1), which is unfit for the parametric tests (Pett 1997).
} 


\section{Kimi Akita}

results suggest, even if they do not guarantee, that magnitude symbolism of consonants and vowels is more effective in mimetic words, although it can work in nonmimetic ones as well. ${ }^{8}$ Note, however, that the inequality in magnitudesymbolic effects observed between the two mimetic templates used in the present experiment suggests the need for consideration of other mimetic templates.

\section{Conclusion}

In this paper, I have claimed that sound-symbolic effects work more effectively in morphophonologically mimetic words than in morphophonologically nonmimetic ones with magnitude symbolism of consonants and vowels as examples. At the moment, we have more positive than negative evidence for the hypothesis. Larger-scale follow-up experiments are expected to clarify the phonosemantically as well as morphophonologically definable status of the Mimetic stratum of Japanese. This clarification will substantiate the alleged existence of the semantic peculiarity that native Japanese speakers' intuitions find for the word class at issue.

There are some specific improvements to be made in future research. First, since the present study employed a mere four-graded scale for rating, it will be useful for clearer discrimination among stimulus words to adopt a scale that allows finer-grained evaluations. Second, we need to extend our observation to other semantic scales than magnitude - softness, roundness, loudness, for example. Finally, we have to examine the sound-symbolic properties of words with various segmental combinations. Investigations in this line will surely contribute to the identification of the fundamental characteristics of sound symbolism and mimetics.

\section{References}

Abelin, Åsa. 1999. Studies in Sound Symbolism. Gothenburg Monographs in Linguistics 17. Göteborg: Göteborg University.

Akashi, Kaori. 2007. Variation of Emphatic Mora Augmentation in Japanese Mimetics. Phonological Studies 10:3-10.

Akita, Kimi. 2008. Onsyootyoogo-no "hantyuuka-mondai"-e-no hitotu-no kotae: Tamori \& Schourup (1999)-e-no ripurai [Defining the mimetic category in the

\footnotetext{
${ }^{8}$ An experiment using existent words as stimuli might give still milder results, for soundsymbolic interpretation tends to be strong in nonwords (Bentley and Varon 1933; Brown 1958; Westbury 2005).

${ }^{9}$ The results for the reduplicative template were more consistent with my prediction than those for the suffixed template. This seems to stem from the templatic magnitude symbolism of the reduplicative construction. As Sharon Inkelas pointed out at the conference, reduplication generally enhances the spatial, temporal, or more abstract size of referent entities, properties, and eventualities, as in Japanese ieie 'houses' (< ie '(a) house') and akaaka 'bright red' (< aka 'red'). Furthermore, we have to consider the possibility that the template $\mathrm{CVCV}^{\wedge}$ ri carries the segmental sound symbolism of /r/ and /i/ as well as a templatic sound symbolism.
} 


\section{Phonosemantic Evidence for the Mimetic Stratum}

Japanese lexicon: A reply to Tamori and Schourup (1999)]. Proceedings of the Eighth Annual Meeting of the Japanese Cognitive Linguistics Society.

Bentley, Madison, and Edith J. Varon. 1933. An Accessory Study of "Phonetic Symbolism." American Journal of Psychology 45(1):76-86.

Brown, Roger. 1958. Words and Things. New York: The Free Press.

Diffloth, Gérard. 1994. /i:/ Big, /a/: Small. In L. Hinton, J. Nichols, and J. J. Ohala, eds., Sound Symbolism, 107-114. Cambridge: Cambridge University Press.

Fukazawa, Haruka, Mafuyu Kitahara, and Mitsuhiko Ota. 1998. Lexical Stratification and Ranking Invariance in Constraint-Based Grammars. CLS 34: The Panels, 47-62. Chicago Linguistic Society.

Hamano, Shoko. 1998. The Sound-Symbolic System of Japanese. Stanford, CA: Center for the Study of Language and Information.

Itô, Junko, and R. Armin Mester. 1995. Japanese Phonology. In J. A. Goldsmith, ed., The Handbook of Phonological Theory, 817-838. Oxford: Blackwell.

Itô, Junko, and R. Armin Mester. 1999. The Phonological Lexicon. In N. Tsujimura, ed., The Handbook of Japanese Linguistics, 62-100. Oxford: Blackwell.

Johnson, Ronald C. 1967. Magnitude Symbolism of English Words. Journal of Verbal Learning and Verbal Behavior 6(4):508-511.

Lu, Chiarung. 2006. Giongo/gitaigo-no hiyuteki-kakutyoo-no syosoo: Nintigengogaku-to ruikeiron-no kanten-kara [Aspects of figurative extensions of mimetics: From Cognitive Linguistic and typological perspectives]. Ph.D. diss., Kyoto University.

Kakehi, Hisao, Ikuhiro Tamori, and Lawrence Schourup. 1996. Dictionary of Iconic Expressions in Japanese. Berlin/New York: Mouton de Gruyter.

Kawahara, Shigeto, Kazuko Shinohara, Akira Nakayama, Shinsuke Oshida, Ikuyo Kaneko, Miko Odate, and Yoshihiro Matsunaka. 2005. Nihongo-no on'insosei-ga kanki-suru imeezi-ni tuite-no zikken-kenkyuu [An experimental study on images evoked by phonological features in Japanese]. Papers from the 22nd Annual Meeting of Japanese Cognitive Science Society.

Kawahara, Shigeto, Kazuko Shinohara, and Yumi Uchimoto. 2008. A Positional Effect in Sound Symbolism: An Experimental Study. Proceedings of the Eighth Annual Meeting of the Japanese Cognitive Linguistics Association.

Kurisu, Kazutaka. 2006. Theoretical Implications of Mimetic Voicing in Japanese. In T. J. Vance and K. Jones, eds., Japanese/Korean Linguistics 14, 5162. Stanford, CA: Center for the Study of Language and Information.

McCawley, James D. 1968. The Phonological of a Grammar of Japanese. The Hague: Mouton.

Magnus, Margaret. 1999. The Gods of the Word: Archetypes in the Consonants. Truman State University Press.

Makino, Seiichi. 2007. An Argument for Non-arbitrary Relationship between Sound and Meaning in Japanese Grammar. In Y. Ikegami, V. Eschbach- 


\section{Kimi Akita}

Szabo, and A. Wlodarczyk, eds., Japanese Linguistics: European Chapter, 239-250. Tokyo: Kurosio.

Miyajima, Tatsuo. 1977. Goi-no taikei [The lexical system]. In S. Oono et al., eds., Nihongo 9: Goi-to imi [Japanese 9: Lexicon and semantics], 1-41. Tokyo: Iwanami.

Newman, Paul. 2001. Are Ideophones Really as Weird and Extra-systematic as Linguists Make Them Out to Be? In F. K. E. Voeltz and Ch. Kilian-Hatz, eds., Ideophones, 251-258. Amsterdam/Philadelphia: John Benjamins.

Pett, Marjorie A. 1997. Nonparametric Statistics for Health Care Research: Statistics for Small Samples and Unusual Distributions. Thousand Oaks/London/New Delhi: SAGE.

Sapir, Edward. 1929. A Study in Phonetic Symbolism. Journal of Experimental Psychology 12(3):225-239.

Shinohara, Kazuko, Shigeto Kawahara, Akira Nakayama, and Yoshihiro Matsunaka. 2007. Onsyootyoo-to sintaisei [Sound symbolism and embodiment]. Kotoba-to ningen: Journal of Human Linguistics Circle 6:1-12.

Tamori, Ikuhiro, and Lawrence Schourup. 1999. Onomatope: Keitai-to imi [Onomatopoeia: Form and meaning]. Tokyo: Kurosio.

Tateishi, Koichi. 2003. Are Borrowed Morphemes Always Foreign? In T. Honma, M. Okazaki, T. Tabata, and S. Tanaka, eds., A New Century of Phonology and Phonological Theory: A Festschrift for Professor Shosuke Haraguchi on the Occasion of His Sixtieth Birthday, 258-267. Tokyo: Kaitakusha.

Tokieda, Motoki et al., eds. 1955. Kokugogaku ziten [A dictionary of Japanese linguistics]. Tokyo: Tokyodo.

Ultan, Russell. 1978. Size-Sound Symbolism. In J. Greenberg, ed., Universals of Human Language, Volume 2: Phonology, 525-568. Stanford, CA: Stanford University Press.

Westbury, Chris. 2005. Implicit Sound Symbolism in Lexical Access: Evidence from an Interference Task. Brain and Language 93(1):10-19.

Wiltshire, Caroline R. 1999. Expressives in Tamil: Evidence for a Word Class. In R. Singh, ed., The Yearbook of South Asian Languages and Linguistics, 119137. New Delhi/Thousand Oaks/London: SAGE.

Yamaguchi, Nakami. 2002. Inu-wa biyo-to naiteita: Nihongo-wa giongo/gitaigoga omosiroi [Dogs were crying biyo: It is mimetics that are interesting in Japanese]. Tokyo: Kobunsha.

Kimi Akita

Department of Linguistics

Graduate School of Humanities and Social Sciences

Kobe University

1-1 Rokko-dai-cho, Nada-ku, Kobe-shi

Hyogo 657-0016 Japan

akitambo@gmail.com 